\title{
Posttraumatic Stress, Psychological Morbidity, Pychopathology, Family Functioning, and Quality of Life in Portuguese War Veterans
}

\author{
M. Graça Pereira', Susana Pedras', and Cristiana Lopes²
}

\begin{abstract}
Thirty-four years after the end of Colonial War, few data are available on the impact of such experience on Portuguese veterans. The purpose of the present study was to assess post-traumatic stress disorder (PTSD), psychological morbidity, psychopathology, family functioning, and quality of life in veterans with and without PTSD diagnosis, to find the best predictors of quality of life and to analyse psychopathology as a mediator in the relationship between traumatic symptoms and quality of life. A total of $10 \mathrm{I}$ male veterans participated in the study. Veterans were recruited from a central hospital and a veterans organization. The instruments used were the Portuguese versions of Posttraumatic Stress Scale (Mclntyre \& Ventura), FACES III (Olson, Portner, \& Lavee), BSI (Derogatis), BDI (Beck, Ward, Mendelson, Mock, \& Erbaugh), STAI (Spielberger, Gorush, Lushene,Vagg, \& Jacobs), and Quality of Life (WHOQOL Group). Results showed quality of life to be significantly related to less depression and anxiety. Veterans with PTSD diagnosis had more psychopathology and less quality of life in all domains. Veterans who belonged to extreme families showed more psychopathology and presented more PTSD symptoms, particularly avoidance and intrusion. When all psychological variables entered in the regression model, depression predicted physical quality of life; trait anxiety predicted psychological quality of life; PTSD predicted social quality of life; and, depression predicted environmental quality of life. Finally, psychopathology was a mediator of the relationship between traumatic symptoms and all domains of quality of life except environmental quality of life. Results emphasize the need for psychological interventions in veterans and their families.
\end{abstract}

\section{Keywords}

veterans, quality of life, family, PTSD, psychopathology

\section{Introduction}

Between 1916 and 1974, nearly a million of young Portuguese troops participated in the Colonial War (Angola, Guinea, and Mozambique), corresponding to $10 \%$ of the country's population. These Portuguese colonies were fighting for their independence. It was only with political change in 1974, and the end of the dictatorship, that Portuguese colonies became independent (Aniceto \& Gomes, 2000). Participation in the Colonial War was mandatory for all military young men. Ten thousand were killed and 40,000 wounded (Maia, McIntyre, Pereira, \& Fernandes, 2006).

Fifty years since the beginning of the war, there are still few data on the prevalence of the impact of the war in Portuguese veterans. Albuquerque and Lopes (1997) estimated that 140,000 Portuguese veterans present chronic psychological disturbances as a result of their participation in the Colonial War. In fact, in a sample of 120 veterans with post-traumatic stress disorder (PTSD), 84.2\% showed chronic PTSD, 98.2\% associated pathology, and $37.7 \%$ severe incapacity. In a sample of ex-marines, Pereira and Monteiro-Ferreira (2006) found that $66 \%$ of veterans fulfilled the criteria for PTSD. Maia and collaborators (2006), in a study with 350 veterans, found that $39 \%$ of veterans fulfilled the criteria for PTSD and 56\% presented psychological morbidity. Pereira and Pedras (2007), in a study with 505 veterans from the Colonial War found $43 \%$ to have PTSD and $36 \%$ to have PTSD symptoms.

PTSD is commonly associated with comorbidity. Nearly $50 \%$ to $90 \%$ of individuals with PTSD show psychological problems such as anxiety, depression, substance abuse, difficulty in interpersonal relationships, physical symptoms, and cognitive impairments (Joseph, Williams, \& Yule, 1997; Yehuda \& Wong, 2002). Other authors (Freedy \& Donkervoet, 1995 ) found substance abuse (73\%), depression (26\%), phobias, and panic disorders to be very prevalent. Orsillo, Heimberg, Juster, and Garret (1996) also found anxiety and

\footnotetext{
'University of Minho, Braga, Portugal

${ }^{2}$ Hospital de Braga, Braga, Portugal

Corresponding Author:

M. Graça Pereira, University of Minho, School of Psychology, 47 I0-057,

Braga, Portugal

Email:gracep@psi.uminho.pt
} 
social phobia to be the most prevalent comorbid disorders. In Portuguese veterans, Albuquerque and Lopes (1997) found identical results. Also, in a study with war veterans from Lebanon War, Ginzburg, Ein-Dor, and Solomon (2010) found that almost one half of war veterans had a lifetime triple comorbidity of PTSD, depression, anxiety, and impaired functioning.

Several studies consider PTSD and depression, together, a vulnerability trait (Breslau, Davis, Peterson, \& Schultz, 2000; Green et al., 2006; O’Donnell, Creamer, \& Pattison, 2004) that is, PTSD a risk factor for depression and depression a risk factor for PTSD development. Therefore, there seems to be a reciprocal relationship between depression and PTSD (Erickson, Wolfe, King, King, \& Sharkansky, 2001). The presence of depression together with a PTSD diagnosis increases psychological distress, substance abuse, relationship problems, and search for psychological help in war veterans (Dunn et al., 1993; Dunn et al., 2004; Roszell, McFall, \& Malas, 1991). Ikin and collaborators (2007) found $32 \%$ of Australia's and Korean War veterans to met criteria for PTSD and 23\% met criteria for depression. More recently, 50 years after Korean War, 17\% of veterans met criteria for comorbid PTSD and depression, 15\% presented PTSD without depression, and 6\% had depression without PTSD (Ikin, Creamer, Sim, \& McKenzie, 2010).

Taft and collaborators (2005) found depression to be a risk factor for aggressiveness in veterans with PTSD. Several studies have shown high levels of hostility associated with violent and poor self-control in veterans (Beckham, Feldman, Kirby, Hertzberg, \& Moore, 1997). Delusional paranoid symptoms have also been associated with PTSD although the relationship is still unclear (Kozaric-Kovacic \& Borovecki, 2005).

Anxiety is also commonly associated to PTSD (Fairbank, Keane, \& Malloy, 1983) and quality of life. Forman-Hoffman and collaborators (2005) found mental health comorbidity affecting several dimensions of health related quality of life. Impairments to quality of life were reported in the areas of physical health (such as mobility and ability to perform activities of daily living), psychological well-being (including self-esteem, mood, and body image), social relationships (such as personal relationships and social support), and in the environment (including financial resources, safety, and access to information) (Ikin et al., 2010). The findings support the perspective that PTSD is the dominant disorder following traumatic events, associated with comorbidity. Anxiety and depression are very common in veterans with PTSD, and the rates for such disturbances are very high when compared to veterans without PTSD (Orsillo et al., 1996).

Somatic complains have been also associated with PTSD (Decoufle, Holmgreen, Boyie, \& Stroup, 1992; Jakupcak et al., 2006) and health complains (Beckham et al., 1998; Maia, McIntyre, Pereira, \& Fernandes, 2010). Among PTSD symptom clusters, numbing symptoms (excluding avoidance) were the best predictors of somatization (Escalona, Achilles,
Waitzkin, \& Yager, 2004). It has been suggested that numbing symptoms are independent of active avoidance and might, in fact, have a different neurobiology (Foa, Riggs, \& Gershuny, 1995). Numbing symptoms may reflect social or emotional disengagement, causing increased awareness of internal sensory perception. It is also possible that some of the numbing symptoms of PTSD overlap with the alexithymia construct, known to be associated with somatization (Escalona et al., 2004).

Taking in consideration PTSD clinical features, it is easy to understand how family functioning may be negatively affected. PTSD has a deleterious impact on interpersonal relationships in general (Roberts et al., 1982), on the family (Jordan et al., 1992), on the couple (Beckham, Lytle, \& Feldman, 1996), and on parenting (Samper, Taft, King, \& King, 2004). In fact, PTSD symptoms have been associated with conflict and with family and couple distress (Beckham et al., 1996; Dekel, Goldblatt, Keidar, Solomon, \& Polliack, 2005; Westerink \& Giarratano, 1999). Veterans' families present low levels of marital satisfaction, low expressiveness and high levels of conflict (Caselli \& Motta, 1995; Hendrix, Jurich, \& Schumm, 1995; Solomon, Mikulincer, Fried, \& Wosner, 1987), low levels of cohesion and adaptability, difficulties in communication (Rosenheck \& Thomson, 1986; Hendrix, Erdmann, \& Briggs, 1998), high levels of isolation (Roberts et al., 1982), and, according to Ford, Shaw, and Sennhauser (1993), low levels of family functioning, low sexual satisfaction, and poor problem resolution. Israel veterans were also described, by their spouses, as less expressive in family interaction (Waysman, Mikulincer, Solomon, \& Weisenberg, 1993). However, it is important to acknowledge that the comorbidity associated with PTSD may be responsible for family dysfunction as much as PTSD itself (Evans, McHugh, Hopwood, \& Watt, 2003). In another study, more than $75 \%$ of returning veterans referred for VA behavioral health evaluations showed difficulties in their marital relationships or in their relationship with their children, and more than $50 \%$ endorsed mild to moderate intimate partner violence (Sayers, Farrow, Ross, \& Oslin, 2009).

Quality of life is often compromised in veterans (Schnurr, Hayes, Lunney, McFall, \& Uddo, 2006; Stein, Walker, Hazen, \& Forde, 1997; Magruder et al., 2004). In fact, PTSD has been associated to a poor perception of physical health and poor social functioning (Golding, 1996; Wolfe, Schnurr, Brown, \& Furey, 1994). In a study that included war veterans with PTSD, 59\% showed a severe impairment in quality of life (Ford et al., 1993). Anxiety and PTSD, when associated to depression, greatly affect quality of life (Mittal, Fortney, Pyne, Edlund, \& Wetherell, 2006). Zatzick and collaborators (1997) studied the impact of PTSD on several domains of quality of life, in a national sample of Vietnam veterans, and found those with PTSD to have more difficulties in all domains of quality of life when compared with veterans with no PTSD. In fact, the authors report that veterans with PTSD had more chronic diseases, low 
well-being, more physical limitations, and more absences from work. Mendlowicz and Stein (2000), in a study with veterans in treatment, found a relationship between severity of symptoms and poor physical and psychosocial quality of life. When veteran's treatment was successful, quality of life increased (Schnurr et al., 2006).

In veterans from former Yugoslavia, 83.7\% still present PTSD and a low self-reported quality of life expressing explicit dissatisfaction with their life in general, particularly, in the domains of employment, finances, leisure activities, and physical and mental health (Priebe et al., 2010). Chronic PTSD in Vietnam veterans has also been associated to decreased well-being, compromised quality of life, poor psychosocial adjustment (Ferrada-Noli, Asberg, Ormstad, Lundin, \& Sundbom, 1998; McFarlane, Atchison, Rafalowicz, \& Papay, 1994; Taft, Stern, King, \& King, 1999), problematic family relationships, less life satisfaction, more mental health services' use, and more nonspecific health complaints at the 14-year follow-up (Koenen, Stellman, Sommer, \& Stellman, 2008).

Based on the literature, the authors expect differences, in Portuguese veterans, on psychopathology and quality of life, according to the presence of PTSD diagnosis, and on anxiety, depression, psychopathology, and PTSD symptoms according to family type. Furthermore, this study also investigates the best predictors of quality of life and the role of psychopathology as a mediator on the relationship between traumatic symptoms and all domains of quality of life.

\section{Method}

\section{Sample}

One hundred and one Portuguese war veterans participated in the study. Veterans were recruited from a psychiatry department of a central hospital and from a veterans organization, both in the north of Portugal. Veterans were all in the process of being evaluated for the purpose of soliciting medical/social assistance from the Portuguese government and were invited to participate in the study after signing the informed consent. A cross-sectional and correlational design was used.

\section{Proceedings}

Veterans answered the questionnaires in a counselling context in the format of an interview by a very experienced trained clinical/health psychologist.

\section{Instruments}

Posttraumatic Stress Scale. This is a Portuguese scale that provides a diagnosis of PTSD according to DSMIV (McIntyre \& Ventura, 1996). The first part is qualitative and descriptive and asks whether the individual has been exposed, in the past, to traumatic events and the emotions associated to it (A criteria). The second part has 17 items that correspond to PTSD symptoms according to DSM IV-R divided by three subscales: Reexperiencing the Event- - this subscale assesses intrusion that corresponds to B criteria (five items, e.g., Have you had many bad dreams or nightmares concerning your traumatic experience at war?). Avoidance - this subscale assesses denial and numbness (C criteria, seven items, e.g., Have you tried not to think or feel similar experiences to those you lived during war?), and, finally, Arousal-this subscale assesses hypervigilance and activation including all the vegetative symptoms (D criteria, five items; e.g., Do you have trouble falling asleep or sleeping through the night?). To receive a PTSD diagnosis, veterans need to respond affirmatively at least to one question from the first subscale, three from the second, and at least two from the last. Cronbach's alpha for the Portuguese version is .79.

State Trait Anxiety Inventory (STAI). STAI is a 40 -items questionnaire that assesses anxiety trait and anxiety state (each subscale with 20 items; (Spielberger et al., 1983; Portuguese version of McIntyre \& McIntyre, 1995). The Portuguese version (McIntyre \& McIntyre, 1995) has an alpha of .92 (trait scale) and .90 (state scale). Norms in the general population for our sample's age group are 34 for trait anxiety and 35 for state anxiety. The inclusion of a measure for general anxiety that has to do with the fact that veterans who do not fill the criteria for PTSD diagnosis, may still present clinical high levels of anxiety that require medical/social and psychological attention.

Beck Depression Inventory (BDI). The BDI is a 21 -items questionnaire that assesses depressive symptoms (Beck, Ward, Mendelsohn, Mock, \& Erbaugh, 1961; Portuguese Version of McIntyre \& McIntyre, 1995). Cronbach's alpha for the Portuguese version is .86. Cutoff scores for severe depression is $\geq 29$.

Family Adaptability and Cohesion Evaluation Scales III (FACES III). FACES III is a 20-item, self-report instrument that assesses family functioning measuring family adaptability and cohesion (Olson et al., 1993; Portuguese Version of Curral et al., 1999). The Adaptability scale assesses child control, discipline, leaderships, roles, and rules. The Cohesion scale evaluates emotional bonding, family boundaries, supportiveness, interests, and recreation. FACES allows for a family to be classified in balanced, midrange, and extreme according to a formula that takes in consideration the responses on both subscales simultaneously. Cronbach's alpha for the Portuguese version of Cohesion scale was .87 and that for the Adaptability scale was .82.

Brief Symptom Inventory (BSI). BSI is a 53-items questionnaire that assesses psychopathological symptoms in 9 basic dimensions: somatization, depression, anxiety, phobic anxiety, hostility, psychoticism, paranoid ideation, interpersonal sensibility, and compulsive obsession (Derogatis, 1993; Portuguese Version of Canavarro, 1999). The instrument provides a Global Severity Index (GSI) that is calculated by summing all the 
responses and dividing by the total number of items. Cutoff scores for the Portuguese population, in clinical samples, is 1.7 (Canavarro, 1999). Cronbach's alpha in this sample for all subscales ranged from .70 to .80 .

World Health Organization Quality of Life. WHOQOLBref is a 26-items instrument that assesses four dimensions of quality of life: physical, social, psychological, and environmental (WHOQOL Group, 1998; Portuguese Version of Canavarro et al., 2007). Cronbach's alpha for the Portuguese version ranged from .64 to .87 .

\section{Data Analysis}

Descriptive statistics were conducted to determine rate of PTSD diagnosis, family type, and presence of psychopathology in the sample. Next, a series of correlations were conducted to identify the relationships among depression, anxiety, and quality of life. Differences between veterans with and without PTSD diagnosis were also performed on all variables. Finally, a multiple regression analysis (method enter) to find the best predictors of quality of life was conducted. Variables introduced in the regression models, in the first block, were: family type, PTSD diagnosis, and presence of psychopathology (GSI $\geq 1.7$ ). In the second block, the variables introduced were depression, state anxiety, and trait anxiety.

Finally, mediation analyses were performed to find out whether psychopathology was a mediator in the relationship between traumatic symptoms and each domain of quality of life following kenny's method (2009).

\section{Results}

\section{Sample}

Sample size consisted of 101 war veterans. Age average for veterans was 59 and ranged from 41 - to 73 -years-old. $82 \%$ had only 4 years of schooling, 92\% were married, $27 \%$ were active in their jobs, and 50\% had already retired.

In terms of war theatre, veterans served in Angola (41\%), Guinea (30\%), and Mozambique (28\%). Most of them were soldiers (88\%) and were part of the Army (91\%). Only 10\% of veterans had served as special troops.

Seventy-one percent of the sample presented psychopathology (GSI $\geq 1.7$ ) showing emotional disturbance in all subscales, particularly, somatization, depression, anxiety, paranoid ideation, and hostility. $47 \%$ presented severe depression $(\geq 29)$ and high-state anxiety $(M=59.8, S D=12.8)$ and trait anxiety $(M=59, S D=10.9)$ much above the scores for normal population $(M=35, S D=11 ; M=34, S D=8.8$, respectively). Forty-five percent of the sample fulfilled criteria for a PTSD diagnosis.

According to FACES classification (Olson, Sprenkle, \& Russel, 1979), 79\% of veterans belonged to extreme families and $20 \%$ to midrange families. No balanced families were found.

Quality of life and psychological morbidity. Quality of life was negatively associated to psychological morbidity (depression, state anxiety, and trait anxiety). As a result, veterans with more depression and anxiety showed less quality of life in all domains. In fact, physical quality of life was negatively associated with state anxiety $(r=-.360, p<.01)$, trait anxiety $(r=$ $-.424, p<.01)$, and depression $(r=-.593, p<.01)$. However, psychological quality of life was also associated with state anxiety $(r=-.484, p<.01)$, trait anxiety $(r=-.506, p<.01)$, and depression $(r=-.643, p<.01)$. The same holded true for social quality of life and environmental quality of life that were also associated to psychological morbidity, respectively: state anxiety $(r=.301, p<.01 ; r=-.298, p<.01)$, trait anxiety $(r=-.343, p<.01 ; r=-.343, p<.01)$, and depression $(r$ $=-.401, p<.01 ; r=-.720, p<.01)$.

Psychopathology, quality of life, and PTSD diagnosis. Results showed veterans with a PTSD diagnosis to have more psychopathology and less quality of life in all domains of quality of life. Table 1 shows the results.

Family type, anxiety, depression, psychopathology and PTSD symptoms. The results showed veterans in extreme families to have more psychopathology and more PTSD symptoms in terms of avoidance and intrusion. No differences were found on depression, anxiety, and hyperarousal. Table 2 shows the results.

Predictors of quality of life. Having less depression is the only variable that predicts better physical quality of life explaining $36 \%$ of the variance. In terms of psychological quality of life, PTSD diagnosis was the only predictor and the model accounted for $23 \%$ of the variance. When depression and anxiety (trait and state) were added, only trait anxiety became the sole predictor, and the final model explained 58\% of the variance. Social quality of life was predicted by PTSD diagnosis and psychopathology, but when other variables entered in the model, such as depression and anxiety (trait and state), PTSD diagnosis became the sole predictor explaining $30 \%$ of the variance. The same holds true for environmental quality of life where PTSD diagnosis and psychopathology were significant predictors. However, when depression and anxiety (trait and state) were added, depression became the only predictor, and the final model explained $53 \%$ of the variance. Table 3 shows the results.

\section{Mediation Analysis}

Results showed traumatic symptoms to be a significant predictor of physical quality of life (path $\mathrm{c} ; \beta=-.385 ; p \leq$ .01 ), and the model explained $13.5 \%$ of variance. Also, traumatic symptoms were a significant predictor of psychopathology (path a; $\beta=.523 ; p \leq .01$ ), and the model explained $26.6 \%$ of variance. When both the mediator (path $b$ ) and the predictor (path c') were entered in the equation, the mediator 
Table I. Differences on Psychopathology and Quality of Life According to PTSD Diagnosis $(N=10 \mathrm{I})$

\begin{tabular}{llccr}
\hline & $\begin{array}{c}\text { PTSD } \\
\text { diagnosis }\end{array}$ & $M$ & SD & Significance \\
\hline $\begin{array}{l}\text { Psychopatology } \\
\text { (GSI) }\end{array}$ & Yes & 132.52 & 37.57 & $.00 I^{* * *}$ \\
& No & 106.57 & 41.38 & \\
$\begin{array}{l}\text { Physical quality } \\
\text { of life }\end{array}$ & Yes & 14.85 & 5.59 & $.034^{*}$ \\
& No & 17.43 & 3.94 & \\
$\begin{array}{l}\text { Psychological } \\
\text { quality of life }\end{array}$ & Yes & 12.75 & 3.65 & $.00 I^{* * *}$ \\
$\begin{array}{l}\text { Social quality } \\
\text { of life }\end{array}$ & Yes & 16.58 & 4.39 & \\
& No & 6.78 & 2.27 & $.000^{* * * *}$ \\
$\begin{array}{l}\text { Environmental } \\
\text { quality of life }\end{array}$ & Yes & 9.06 & 1.86 & \\
\hline
\end{tabular}

$* p \leq .05 . * * * p \leq .001$.

was significant $(\beta=-.308 ; p \leq .01)$ and the predictor was not $(\beta=-.238, n s)$. The model explained $19.8 \%$ of variance. Therefore, psychopathology was a partial mediator of the relationship between traumatic symptoms and physical quality of life. The strength of the mediation was $23 \%$.

The same procedure was tested for psychological quality of life, social quality of life, and environmental quality of life. Results showed traumatic symptoms to be a significant predictor of psychological quality of life (path c; $\beta=-.544 ; p \leq$ .01 ) and the model explained $28.5 \%$ of variance. Also, traumatic symptoms were a significant predictor of psychopathology (path $\mathrm{a} ; \beta=.523 ; p \leq .01$ ) and the model explained $26.6 \%$ of variance. When both the mediator (path $b$ ) and the predictor (path c') were entered in the equation, the mediator was significant $(\beta=-.2 .564 ; p \leq .01)$ and so was the predictor $(\beta=$ $-.406 ; p \leq .01)$. The model explained $34 \%$ of variance. Therefore psychopathology was a partial mediator of the relationship between traumatic symptoms and psychological quality of life. The strength of the mediation was $28 \%$. Results also showed traumatic symptoms to be a significant predictor of social quality of life (path c; $\beta=-.349 ; p \leq .01$ ), and the model explained $11 \%$ of variance. Also, traumatic symptoms was a significant predictor of psychopathology (path a; $\beta=$ $.523 ; p \leq .01$ ), and the model explained $26.6 \%$ of variance. When both the mediator (path b) and the predictor (path c') were entered in the equation, the mediator was significant $(\beta=$ $-.337 ; p \leq .01)$ and the predictor was not $(\beta=-.170, n s)$. The model explained $18 \%$ of variance. Therefore, psychopathology was a partial mediator of the relationship between traumatic symptoms and social quality of life. The strength of the mediation was $51 \%$. Table 4 shows the results.

Finally, results showed that psychopathology was not a mediator of the relationship between traumatic symptoms and environmental quality of life.

\section{Discussion}

In this sample, $45 \%$ of war veterans fulfilled criteria for PTSD diagnosis. This result is higher compared to other Portuguese studies (Maia et al., 2006). However, since the sample is composed of veterans who are requesting medical/ social help from the Portuguese Government, these figures may be expected. The authors would like to emphasize that PTSD diagnosis was given based on the results of the Posttraumatic Stress Scale, as mentioned before, a clinical interview by an experienced psychologist and a psychiatric evaluation that confirmed PTSD diagnosis.

The great majority of veterans presented psychopathology $(71 \%)$ and those with PTSD diagnosis showed more somatization, depression, anxiety, hostility, and paranoid ideation. In fact, Pereira and Monteiro-Ferreira (2006), in a Portuguese sample of war veterans, found high levels of psychopathology, using the Brief Symptom Inventory (Derogatis, 1993). Therefore, results of the present study are in accordance with other studies (Beckham et al., 1997; KozaricKovacic \& Borovecki, 2005) that show PTSD as a complex disorder with several implications on mental health.

Results showed also high levels of depression (78\% show moderate to severe depression) and high anxiety in veterans without PTSD diagnosis. These results are in accordance with the literature. Fairbank and collaborators (1983) and Orsillo and collaborators (1996) found moderate to severe levels of depression and also high anxiety in Vietnam veterans. Moreau and Zisook (2002) found more depressive and anxiety symptoms in war veterans without PTSD than in those with a diagnosis of PTSD.

Twenty-one percent of veterans belonged to midrange families and $78 \%$ to extreme families. No balanced families were found. These results are in accordance with Jordan and collaborators (1992) who found veterans' to belong to extreme families (49\%) and midrange families (36\%). The authors also found families with veterans, without PTSD diagnosis, to be less classified as extreme families (31\%) and more as midrange families $(21 \%)$. Other studies have found veterans families as presenting low levels of expressiveness, low cohesion, high levels of conflict (Carroll, Rueger, Foy, \& Donahoe, 1985; Solomon et al., 1987), low flexibility, and low role adaptation (Verbosky \& Ryan, 1988; Nelson \& Wright, 1996), that is, all traits that characterize extreme and midrange families. Waysman and collaborators (1993) found $19 \%$ of midrange families in a sample of war veterans. However, psychopathology may be a mediator in the relationship between PTSD and family functioning (Jordan et al., 1992). In fact, family functioning may also be a good variable to differentiate PTSD versus non-PTSD veterans' in families (Frye \& Stockton 1982; Waysman et al., 1993). Future studies should test these hypotheses.

Results also show intrusion and avoidance as the most prevalent PTSD symptoms in extreme families such as results found in other studies (Evans et al., 2003; Hendrix et .al., 1998; Rosenheck \& Thompson, 1986). Frederikson, 
Table 2. Results of the T test according to Family Type on Anxiety, Depression, Psychopathology and PTSD Symptoms $(N=|0|)$

\begin{tabular}{llrcc}
\hline & $\begin{array}{c}\text { Type of } \\
\text { family }\end{array}$ & \multicolumn{1}{c}{$M$} & SD & Significance \\
\hline Psychopatology- & Midrange & 96.88 & 45.37 & $.022^{*}$ \\
BSI & Extreme & 122.25 & 39.81 & \\
Depression-BDI & Midrange & 24.76 & 12.97 & .063 \\
& Extreme & 30.11 & 11.25 & \\
Anxiety-STAI & Midrange & 57.75 & 16.12 & .500 \\
(state) & Extreme & 59.93 & 11.98 & \\
Anxiety-STAI & Midrange & 59.65 & 12.16 & .766 \\
(trait) & Extreme & 58.81 & 10.97 & \\
PTSD & Midrange & 3.666 & 0.3261 & .184 \\
hyperarousal & Extreme & 4.087 & 0.1368 & \\
PTSD avoidance & Midrange & 3.700 & 2.002 & $.005^{*}$ \\
& Extreme & 4.975 & 1.735 & \\
PTSD intrusion & Midrange & 3.000 & 1.521 & $.001 * *$ \\
& Extreme & 4.125 & 1.226 & \\
\hline
\end{tabular}

$*_{p} \leq .05 . * *_{p} \leq .001$.

Chamberlain, and Long (1996) found avoidance and numbing as the most difficult issues faced by veterans' families with a negative impact on family communication, affection, and trust. Symptoms of numbing/avoidance have also been associated to less satisfaction with social life (Shea, Vujanovic, Mansfield, Sevin, \& Liu, 2010) and more somatization (Maia et al., 2010).

Veterans with PTSD showed less quality of life in all domains except physical quality of life. This particular result is not in accordance with the literature and may be explained by the high level of somatization presented in the sample. The authors believe, that most of the veterans, regardless of PTSD diagnosis, in the present study, presented poor physical quality of life, and as a result, they were a very homogenous group and no differences could be found between the two groups, according to PTSD diagnosis.

Results also showed psychopathology (GSI $\geq 1.7)$ and PTSD diagnosis to be predictors of low social quality of life. This result may be associated with high rates of avoidance and intrusion symptoms found in the sample. Depression is the sole variable predicting physical quality of life and anxiety, however, it is the most important predictor of psychological quality of life emphasizing the importance of comorbidity associated with PTSD diagnosis. Such results are in accordance with the literature showing depression to be the main negative contributor to health satisfaction in veterans (Rauch et al., 2010).

Finally, family type was not a predictor of quality of life, and this result may be due to the fact that most of veterans families were extreme families and almost no variance was found regarding this variable in the sample.
Mediation analysis showed psychopathology to mediate the relationship between traumatic symptoms and all domains of quality of life except environmental. The mediation was stronger for social quality of life. Comorbidity was also associated with physical symptoms and therefore with quality of life (Dobie et al., 2004). These results highlight the importance of comorbidity on quality of life and are in accordance with the literature (Joseph et al., 1997; Yehuda \& Wong, 2002). Environmental quality of life deals with aspects related to housing, money, and environment safety and therefore are less influenced by psychopathology.

\section{Limitations}

The fact that all veterans, in our sample, were seeking medical/social assistance from the Portuguese government was a limitation. However, this was the best possible clinical sample to study in Portugal. The authors would like to inform that veterans do not need a PTSD diagnosis to receive medical/social assistance from the government. In fact, the presence of psychopathology, traumatic symptoms, and low quality of life are enough for veterans to receive psychological assistance from the Portuguese Association of Veterans Affairs. However, few veterans do so and the great majority asks for help at their local health services.

Veterans who want financial help from the government have to undergo a thoroughly psychiatric and psychological evaluation. The present study focused only on the psychological evaluation of those who submit themselves to that process. Psychological evaluation was conducted in an interview format by a very experienced clinical/health psychologist trained for that purpose. Nevertheless, due to the comorbidity of medical issues and psychological morbidity, the results of this study need to be interpreted cautiously.

The fact that the sample was only collected in the north of the country is also a limitation. However, the great majority (more than 2/3) of Portuguese war veterans came from the north region.

\section{Conclusion}

Fifty years have passed since the beginning of Colonial War, and Portuguese veterans are still showing high levels of distress. In fact, results from this study show high levels of psychopathology, PTSD diagnosis, high morbidity, and a very high percentage of disturbed families in Portuguese war veterans. These results may also explain why veterans are high consumers of health services and are still in treatment many years later (Arbanas, 2010; Hidalgo \& Davidson, 2000; Kessler, 2000).

Due to the high rates of clinical disturbance found in Portuguese veterans, the authors believe Portuguese health services should be sensitive to this problem and be able to 
Table 3. Predictors of Physical, Psychological, Social, and Environment Quality of Life $(N=I 0 I)$

\begin{tabular}{|c|c|c|c|c|c|c|c|c|c|c|c|c|c|c|c|c|}
\hline \multirow[b]{3}{*}{ Variables } & \multicolumn{16}{|c|}{ Predictors } \\
\hline & \multicolumn{4}{|c|}{ Physical quality of life } & \multicolumn{4}{|c|}{ Psychological quality of life } & \multicolumn{4}{|c|}{ Social quality of life } & \multicolumn{4}{|c|}{ Environment quality of life } \\
\hline & $\Delta R^{2}$ & $B$ & SE B & $\beta$ & $\Delta R^{2}$ & $B$ & SE B & $\beta$ & $\Delta R^{2}$ & $B$ & SE B & $\beta$ & $\Delta R^{2}$ & $B$ & $S E B$ & $\beta$ \\
\hline Step I & .145 & & & & .268 & & & & .301 & & & & .211 & & & \\
\hline Family type & & -1.46 & 4.720 & -.039 & & 0.455 & 4.193 & .013 & & 1.27 & 2.031 & .073 & & -1.18 & 4.264 & -.033 \\
\hline PTSD diagnosis & & -2.43 & 1.332 & -.233 & & -3.23 & 1.183 & $-.323 * *$ & & -2.04 & 0.587 & $-.408 * *$ & & -2.59 & 1.203 & $-.264 *$ \\
\hline Psychopathology & & $\begin{array}{c}-2.67 \\
R^{2} \mathrm{Ad}\end{array}$ & $\begin{array}{r}1.580 \\
\text { dj.:. } 100\end{array}$ & -.233 & & $\begin{array}{r}-3.67 \\
R^{2} \mathrm{~A}\end{array}$ & $\begin{array}{c}1.403 \\
\text { dj.:. } .230\end{array}$ & -.320 & & $\begin{array}{r}-1.53^{*} \\
R^{2} \mathrm{~A}\end{array}$ & $\begin{array}{c}0.682 \\
\text { dj.: .230 }\end{array}$ & $-.273^{*}$ & & $\begin{array}{r}-3.29 * \\
R^{2} A\end{array}$ & $\begin{array}{r}1.427 \\
\text { dj.:. } 170\end{array}$ & -.292 \\
\hline Step 2 & .282 & & & & .354 & & & & .073 & & & & .367 & & & \\
\hline Family type & & 0.704 & 4.038 & .019 & & 1.966 & 3.149 & .055 & & 1.33 & 2.011 & .076 & & 1.19 & 3.257 & .034 \\
\hline PTSD diagnosis & & -0.420 & 1.218 & -.040 & & -1.068 & 0.950 & -.107 & & -1.726 & 0.615 & $-.346 * *$ & & -0.688 & 0.982 & -.070 \\
\hline Psychopathology & & 0.773 & 1.566 & .065 & & 0.045 & 1.221 & .004 & & -0.977 & 0.783 & -.174 & & -0.053 & 1.263 & -.005 \\
\hline Depression & & -0.166 & 0.068 & $-.379 * *$ & & -0.096 & 0.053 & -.227 & & -0.003 & 0.035 & -.113 & & -2.04 & 0.055 & $-.493 * *$ \\
\hline Anxiety (state) & & -0.016 & 0.082 & -.038 & & -0.045 & 0.064 & -.110 & & 0.016 & 0.081 & .381 & & 0.053 & 0.066 & .133 \\
\hline Anxiety (trait) & & $\begin{array}{r}-0.150 \\
R^{2} \mathrm{Ad}\end{array}$ & $\begin{array}{c}0.083 \\
\text { dj.: } .364\end{array}$ & -.318 & & $\begin{array}{r}-0.216 \\
R^{2} \mathrm{~A}\end{array}$ & $\begin{array}{r}0.065 \\
\text { dj... } .581\end{array}$ & $-.478^{* *}$ & & $\begin{array}{r}-0.079 \\
R^{2} A\end{array}$ & $\begin{array}{c}0.042 \\
\text { dj.: .532 }\end{array}$ & -.352 & & $\begin{array}{r}-0.184 \\
R^{2} A c\end{array}$ & $\begin{array}{c}0.067 \\
\text { dj.: } .532\end{array}$ & -.416 \\
\hline
\end{tabular}

$p \leq .01 . * * p<.01 . * * * p<.001$.

Table 4. Psychopathology (IGS) as Mediator Between Traumatic Symptoms and Quality of Life $(N=10 \mathrm{I})$

\begin{tabular}{|c|c|c|c|c|c|c|c|c|c|}
\hline \multirow[b]{2}{*}{ Predictors/outcomes } & \multicolumn{3}{|c|}{ Physical quality of life } & \multicolumn{3}{|c|}{ Psychological quality of life } & \multicolumn{3}{|c|}{ Social quality of life } \\
\hline & $\Delta R^{2}$ & $B(S E B)$ & $\beta$ & $\Delta R^{2}$ & $B(S E B)$ & $\beta$ & $\Delta R^{2}$ & $B(S E B)$ & $\beta$ \\
\hline \multicolumn{10}{|l|}{$\begin{array}{l}\text { A.Traumatic Symptoms/ } \\
\text { Quality of Life (path c) }\end{array}$} \\
\hline Traumatic Symptoms & .148 & \multicolumn{2}{|c|}{ Total Adj. $R^{2}=13.5 \%$} & \multicolumn{3}{|c|}{ Total Adj. $R^{2}=28.5 \%$} & \multicolumn{3}{|c|}{ Total Adj. $R^{2}=11 \%$} \\
\hline \multicolumn{10}{|l|}{$\begin{array}{l}\text { B. Traumatic symptoms/ } \\
\text { IGS ( path a) }\end{array}$} \\
\hline Traumatic Symptoms & .274 & \multicolumn{2}{|c|}{ Total Adj. $R^{2}=26.6 \%$} & \multicolumn{3}{|c|}{ Total Adj. $R^{2}=26.6 \%$} & \multicolumn{3}{|c|}{ Total Adj. $R^{2}=26.6 \%$} \\
\hline $\begin{array}{l}\text { C. Traumatic Symptoms/ } \\
\text { Quality of Life/ IGS (path b) }\end{array}$ & .222 & $-.035(.014)$ & $-.308^{*}$ & .361 & $-.032(-.013)$ & $-.289 *$ & .203 & $-.019(.007)$ & $-.377^{* *}$ \\
\hline Traumatic Symptoms (path c') & \multicolumn{3}{|c|}{ Total Adj. $R^{2}=19.8 \%$} & \multicolumn{3}{|c|}{ Total Adj. $R^{2}=34 \%$} & \multicolumn{3}{|c|}{ Total Adj. $R^{2}=18 \%$} \\
\hline
\end{tabular}

$* * p<.01 . * * * p<.001$.

screen psychopathology and PTSD referring veterans to appropriate services to increase their quality of life.

Family interventions are also important, particularly in veterans with PTSD, as the rate of extreme families found was very high according to the results. In fact, Portuguese veterans' wives have shown high rates of secondary traumatic stress disorder (STSD; Pereira \& Monteiro-Ferreira, 2006). Veterans, however, also express interest in greater family involvement (Batten et al., 2009). Future research should assess quality of life and family functioning in veterans' partners and focus on veterans' offspring, as well, to intervene, as soon as possible, in the second generation.

\section{Authors' Note}

This article was presented on the $\mathrm{X}$ International Congress on Traumatic Stress in 2009, Buenos Aires, Argentina.

\section{Declaration of Conflicting Interests}

The authors declared no potential conflicts of interest with respect to the research, authorship, and/or publication of this article.

\section{Funding}

The authors received no financial support for the research, authorship, and/or publication of this article. 


\section{References}

Albuquerque, A., \& Lopes, F. (1997). Stress de Guerra: A ferida encoberta [Stress of war: The hidden wound]. Revista de Psiquiatria: Hospital Júlio de Matos, 1, 47-56.

Aniceto, A., \& Gomes, C. (2000). A Guerra Colonial [The Colonial War]. Lisbon, Portugal: Editorial Noticias.

Arbanas, G. (2010). Patients with combat related and war related posttraumatic stress disorder 10 years after diagnosis. Croatian Medicine Journal, 51, 209-214.

Batten, S. V., Drapalski, A. L., Decker, M. L., DeViva, J., Morris, L. J., Mann, M.A., \& Dixon, L. B. (2009). Veteran interest in family involvement in PTSD treatment. Psychological Services, 6(3), 184-189.

Beck, A., Ward, C., Mendelson, M., Mock, J., \& Erbaugh, J. (1961). An inventory for measuring depression. Archive General Psychiatry, 4, 561-571.

Beckham, J. C., Feldman, M. E., Kirby, A. C., Hertzberg, M. A., \& Moore, S. D. (1997). Interpersonal violence and its correlates in Vietnam veterans with chronic posttraumatic stress disorder. Journal of Clinical Psychology, 53, 859-869.

Beckham, J. C., Lytle, B., \& Feldman, M. (1996). Caregiver burden in partners of Vietnam War veterans with PTSD. Journal of Consulting and Clinical Psychology, 64, 1068-1072.

Beckham, J. C., Moore, S. D., Feldman, M. E., Hertzberg, J. R., Kirby, A. C., \& Fairbank, J. A. (1998). Health status, somatization, and symptom severity of posttraumatic stress disorder in combat veterans with posttraumatic stress disorder. American Journal of Psychiatry, 155, 1565-1569.

Breslau, N., Davis, G. C., Peterson, E. L., \& Schultz, L. R. (2000). A second look at comorbidity in victims of trauma: The posttraumatic stress disorder-major depression connection. Biological Psychiatry, 48, 902-909.

Canavarro, M. C., Simões, M. R., Vaz Serra, A., Pereira, M., Rijo, D., Quartilho, M. J., .. . Carona, C. (2007). Instrumento de Avaliação da Qualidade de Vida da Organização Mundial de Saúde: WHOQOL-Bref [Assessment Tool for Quality of Life of the World Health Organization: WHOQOL-Bref]. In L. Almeida, M. Simões, C. Machado, \& M. Gonçalves (Eds.), Avaliação psicológica: Instrumentos validados para a população Portuguesa (Vol. III, pp. 77-100). Coimbra, Portugal: Quarteto Editora.

Canavarro, M. C. (1999). Inventário de Sintomas PsicopatológicosB.S.I. [Psychopathological Symptoms Inventory]. In M. R. Simões, M. M. Gonçalves, \& L. S. Almeida (Eds.), Testes e provas psicológicas em Portugal (Vol. 2, pp. 95-109). Braga, Portugal: APPORT/SHO.

Carroll, E., Rueger, D., Foy, D., \& Donahoe, C. (1985). Vietnam combat veterans with posttraumatic stress disorder: Analysis of marital and cohabitating adjustment. Journal of Abnormal Psychology, 94, 329-337.

Caselli, L. T., \& Motta, R. W. (1995). The effects of PTSD and combat levels on Vietnam veteran's perceptions of child behavior and marital adjustment. Journal of Clinical Psychology, 51, $5-12$.
Curral, R., Dourado, F., Roma-Torres, A., Barros, H., Palha, A., \& Almeida, L. (1999). Coesão e adaptabilidade familiares numa amostra portuguesa: Estudo com o Faces III [Family cohesion and adaptability in a Portuguese sample: Study with the Faces III]. Psiquiatria Clínica, 20, 213-217.

Decoufle, P., Holmgreen, P., Boyie, C. A., \& Stroup, N. E. (1992). Self-reported health status of Vietnam veterans in relation to perceived exposure to herbicides and combat. American Journal of Epidemiology, 135, 312-323.

Dekel, R., Goldblatt, H., Keidar, M., Solomon, Z., \& Polliack, M. (2005). Being a wife of a veteran with PTSD. Family Relations, 54, 24-36.

Derogatis, L. R. (1993). SCL-90: Administration, scoring and procedures manual. Baltimore, MD: Clinical Psychometric Research.

Dobie, D. J., Kivlahan, D. R., Maynard, C., Bush, K. R., Davis, T. M., \& Bradley, K. A. (2004). Posttraumatic stress disorder in female veterans: association with self-reported health problems and functional impairment. Archives of Internal Medicine, 164, 394-400.

Dunn, N. J., Denney, L., Blackburn, A., Garcia, J., Wurth, M., Stulb, V., . . Perry, B. D. (1993, October). Stereotypes of the VietNam vet: Experiences of the Houston VAMC PTSD specialty clinic. Poster presented at the annual meeting of the International Society for Traumatic Stress Studies, San Antonio, TX.

Dunn, N., Yanasak, E., Schillaci, J., Simotas, S., Rehm, L., Souchek, J., . . Hamilton, J. D. (2004). Personality disorders in veterans with posttraumatic stress disorder and depression. Journal of Traumatic Stress, 17(1), 75-82.

Erickson, D., Wolfe, J., King, D., King, L., \& Sharkansky, E. (2001). Posttraumatic stress disorder and depression symptoms in a sample of Gulf War veterans: A prospective analysis. Journal of Consulting and Clinical Psychology, 69(1), 41-49.

Escalona, R., Achilles, G., Waitzkin, H., \& Yager, J. (2004). PTSD and somatization in women treated at a VA Primary Care Clinic. Psychosomatics, 45, 291-296.

Evans, L., McHugh, T., Hopwood, M., \& Watt, C. (2003). Chronic posttraumatic stress disorder and family functioning of Vietnam veterans and their partners. Australian and New Zealand Journal of Psychiatry, 37, 765-772.

Fairbank, J., Keane, T., \& Malloy, P. (1983). Some preliminary data on the psychological characteristics of Vietnam veterans with posttraumatic stress disorders. Journal of Consulting and Clinical Psychology, 51, 912-919.

Ferrada-Noli, M., Asberg, M., Ormstad, K., Lundin, T., \& Sundbom, E. (1998). Suicidal behavior after severe trauma. Part 1: PTSD diagnoses, psychiatric comorbidity and assessment of suicidal behavior. Journal of Traumatic Stress, 11(1), 103-112.

Foa, E. B., Riggs, D. S., \& Gershuny, B. S. (1995). Arousal, numbing and intrusion: Symptom structure of PTSD following assault. American Journal of Psychiatric Association, 152, 116-120.

Ford, J. D., Shaw, D., \& Sennhauser, S. (1993). Psychological debriefing after Operation Desert Storm, Marital and family assessment and intervention. Journal of Social Issues, 49, 73-102. 
Forman-Hoffman, V. L., Carney, C. P., Sampson, T. R., Peloso, P. M., Woolson, R. F., Black, D. W., . . Doebbeling, B. N. (2005). Mental health comorbidity patterns and impact on quality of life among veterans serving during the first Gulf War. Quality of Life Research, 14, 2303-2314.

Frederikson, L. G., Chamberlain, K., \& Long, N. (1996). Unacknowledged casualties of the Vietnam War: Experiences of the partners of New Zealand Veterans. Qualitative Research, 6(1), 49-70.

Freedy, J., \& Donkervoet, J. (1995). Traumatic stress: An overview of the field. In J. R. Freedy \& S. E. Hobfoll (Eds.), Traumatic stress: From theory to practice (pp. 1-28). New York, NY: Plenum Press.

Frye, J. S., \& Stockton, R. A. (1982). Discriminant analysis of PTSD among a group of Vietnam veterans. American Journal of Psychiatry, 139, 52-56.

Ginzburg, K., Ein-Dor, T., \& Solomon, Z. (2010). Comorbidity of posttraumatic stress disorder, anxiety and depression: A 20-year longitudinal study of war veterans. Journal of Affective Disorder, 123, 249-257.

Golding, J. (1996). Sexual assault history and limitations in physical functioning in two general population samples. Research in Nursing \& Health, 19, 33-44.

Green, B., Krupnick, J., Chung, J., Siddique, J., Krause, E., Revicki, D., . . Miranda, J. (2006). Impact of PTSD comorbidity on one-year outcomes in a depression trial. Journal of Clinical Psychology, $62,815-835$.

Hendrix, C., Erdmann, M., \& Briggs, K. (1998). Impact of Vietnam veteran's arousal and avoidance on spouses perceptions of family life. American Journal of Family Therapy, 26, 115-128.

Hendrix, C. C., Jurich, A. P., \& Schumm, W. R. (1995). Long term impact of Vietnam service on family environmental and satisfaction. Families in Society, 76, 498-506.

Hidalgo, B., \& Davidson, J. R. T. (2000). Posttraumatic stress disorder: Epidemiology and health-related considerations. Journal of Clinical Psychology, 61(Suppl. 7), 5-13.

Ikin, J. F., Creamer, M. C., Sim, M. R., \& McKenzie, D. P. (2010). Comorbidity of PTSD and depression in Korean War veterans: Prevalence, predictors, and impairment. Journal of Affective Disorders, 125, 279-286.

Ikin, J. F., Sim, M. R., Mckenzie, D. P., Horsley, K. W., Wilson, E. J., Moore, M. R., . . . Henderson, S. (2007). Anxiety, post-traumatic stress disorder and depression in Korean War veterans 50 years after the war. British Journal of Psychiatry, 190, 475-483.

Jakupcak, M., Osborne, T., Michael, S., Cook, J., Albrizio, P., \& McFall, M. (2006). Anxiety, sensitivity and depression: Mechanisms for understanding somatic complaints in veterans with posttraumatic stress disorder. Journal of Traumatic Stress, 19 , 471-479.

Jordan, K. B., Marmar, C. R., Fairbank, J. A., Schlenger, W. E., Kulka, R. A., Hough, R. L., \& Weiss, D. S. (1992). Problems in family of male Vietnam Veterans with posttraumatic stress disorder. Journal of Consulting and Clinical Psychology, 60, 916-926.
Joseph, S., Williams, R., \& Yule, W. (1997). Understanding posttraumatic stress: A psychosocial perspective on PTSD and treatment. Chichester, UK: Wiley.

Kenny, D. (2009). Mediation. Retrieved from http://davidakenny. net $/ \mathrm{cm} /$ mediate.htm

Kessler, R. C. (2000). Posttraumatic stress disorder: The burden to the individual and to society. Journal of Clinical Psychiatry, 61(Suppl. 5), 4-14.

Koenen, K. C., Stellman, S. D., Sommer, J. F., \& Stellman, J. M. (2008). Persisting posttraumatic stress disorder symptoms and their relationship to functioning in Vietnam veterans: A 14 year follow up. Journal of Traumatic Stress, 21(1), 49-57.

Kozaric-Kovacic, D., \& Borovecki, A. (2005). Prevalence of psychotic comorbidity in combat-related posttraumatic stress disorder. Military Medicine, 170, 223-226.

Magruder, K., Frueh, B., Knapp, R., Johnson, M., Vaugham, J., Carson, T., . . . Hebert, R. (2004). PTSD symptoms, demographic characteristics, and functional status among veterans treated in VA primary care clinics. Journal of Traumatic Stress, 17, 293-301.

Maia, A., McIntyre, T., Pereira, M. G., \& Fernandes, E. (2006). Por baixo das pústulas da Guerra: Reflexões sobre um estudo com Ex-combatentes da Guerra colonial [Beneath the pustules of War: Reflections on a study of Ex-combatants Colonial War]. In Manuel Gama (Ed.), A Guerra Colonial (1961-1974) (pp. 11-28). Braga, Portugal: Centro de Estudos Lusíadas/Universidade do Minho.

Maia, A., McIntyre, T., Pereira, M. G., \& Fernandes, E. (2010). War exposure, post-traumatic stress, and psychopathology as predictors of Portuguese colonial war veterans' physical health. Anxiety, Stress \& Coping, 13, 1-17.

McFarlane, A. C., Atchison, M., Rafalowicz, E., \& Papay, P. (1994). Physical symptoms in posttraumatic stress disorder. Journal of Psychosomatic Research, 42, 607-617.

McIntyre, T., \& McIntyre, S. (1995). Versão Portuguesa do Beck Depression Inventory (BDI) [Portuguese version of the Beck Depression Inventory (BDI)]. Braga, Portugal: University of Minho.

McIntyre, T., \& McIntyre, S. (1995). State Trait Anxiety Inventory (STAI) (Research version). Braga, Portugal: University of Minho.

McIntyre, T., \& Ventura, M. (1996). Escala de avaliação da resposta aos acontecimentos traumáticos (EARAT) [Rating scale of the response to traumatic events]. In L. Almeida et al. (Org.), Avaliação Psicológica: Formas e contextos (Volume V, pp. 37-44). Braga, Portugal: University of Minho.

Mendlowicz, M., \& Stein, M. (2000). Quality of life in individuals with anxiety disorders. American Journal of Psychiatry, 157, 669-682.

Mittal, D., Fortney, J., Pyne, J., Edlund, M., \& Wetherell, J. (2006). Impact of comorbid anxiety disorders on health-related quality of life among patients with major depressive disorder. Psychiatric Services, 57, 1731-1737.

Moreau, C., \& Zisook, S. (2002). Rational for a posttraumatic stress spectrum disorder. Psychiatric Clinics of North America, 25, 775-790. 
Nelson, B., \& Wright, D. W. (1996). Understanding and treating post-traumatic stress disorder symptoms in female partners of veterans with PTSD. Journal of Marital and Family Therapy, 22, 455-467.

O’Donnell, M. L., Creamer, M., \& Pattison, P. (2004). Posttraumatic stress disorder and depression following trauma: Understanding comorbidity. American Journal of Psychiatry, 161, 1390-1396.

Olson, D. H., Sprenkle, D. H., \& Russel, C. (1979). Circumplex model of marital and family systems: I. Cohesion and adaptability dimensions, family types and clinical applications. Family Process, 18, 3-28.

Olson, D., Portner, J., \& Lavee, Y. (1993). Family Adaptability and Cohesion Evaluation Scale-III. University of Minnesota, Family Social Science, Saint Paul.

Orsillo, S., Heimberg, R., Juster, H., \& Garret, J. (1996). Social Phobia and PTSD in Vietnam Veterans. Journal of Traumatic Stress, 9, 235-252.

Pereira, M. G., \& Monteiro-Ferreira, J. (2006). Variáveis psicossociais e traumatização secundária em mulheres de ex-combatentes da guerra colonial [Psychosocial variables and secondary traumatization in women ex-combatants of the Colonial War]. In P. J. Costa, C. L. Pires, J. Veloso, \& C. L. Pires (Eds.). Stresse Pós Traumático: Modelos Abordagens e Praticas (pp. 37-46). Leiria: Editorial Diferença.

Pereira, M. G., \& Pedras, S. (2007). Características Sócio Demográficas e de PTSD do Veterano de Guerra: Implicações para a Intervenção [Sociodemographic characteristics of the PTSD veterans: Implications for intervention]. Paper presented at the 2nd International Symposium on Post Traumatic Stress Disorder, Portalegre, Portugal.

Priebe, S., Gavrilovic, J. J., Matanov, A., Franciskovic, T., Knezevic, G., Ljubotina, D., . . . Schützwohl, M. (2010). Treatment outcomes and costs at specialized centers for the treatment of PTSD after the War in former Yugoslavia. Psychiatric Service, 61, 598-604.

Rauch, S., Favorite, T., Giardino, N., Porcari, C., Defever, E., \& Israel, L. (2010). Relationship between anxiety, depression and health satisfaction among veterans with PTSD. Journal of Affective Disorders, 121(1), 165-168.

Roberts, W., Penk, W., Gearing, M., Robinowitz, R., Dolan, M., \& Patterson, E. (1982). Interpersonal problems of Vietnam combat veterans with symptoms of posttraumatic stress disorder. Journal of Abnormal Psychology, 91, 444-450.

Rosenheck, R., \& Thomson, J. (1986). Detoxification of Vietnam War trauma: A combined family-individual approach. Family Process, 25, 559-570.

Roszell, D. K., McFall, M. E., \& Malas, K. L. (1991). Frequency of symptoms and concurrent psychiatric disorder in Vietnam veterans with chronic PTSD. Hospital and Community Psychiatry, 42, 293-296.

Samper, R. E., Taft, C. T., King, D. W., \& King, L. A. (2004). Posttraumatic stress disorder symptoms and parenting satisfaction among a national sample of male Vietnam veterans. Journal of Traumatic Stress, 17, 311-315.

Sayers, S. L., Farrow, V. A., Ross, J., \& Oslin, D. W. (2009). Family problems among recently returned military veterans referred for a mental health evaluation. Journal of Clinical Psychiatry, 70, 163-170.

Schnurr, P., Hayes, A., Lunney, C., McFall, M., \& Uddo, M. (2006). Longitudinal analysis of the relationship between symptoms and quality of life in veterans treated for posttraumatic stress disorder. Journal of Consulting and Clinical Psychology, 74, 707-713.

Shea, M. T., Vujanovic, A. K., Mansfield, A. K., Sevin, E., \& Liu, F. (2010). Posttraumatic stress disorder symptoms and functional impairment among OEF and OIF National Guard and Reserve veterans. Journal of Traumatic Stress, 23, 100-107.

Solomon, Z., Mikulincer, M., Fried, B., \& Wosner, Y. (1987). Family characteristics and posttraumatic stress disorder: A followup of Israeli combat stress reaction casualties. Family Process, 26, 383-394.

Spielberger, C., Gorush, R., Lushene, R., Vagg, P., \& Jacobs, G. (1983). Manual for the State-Trait Anxiety Inventory. Palo Alto, CA: Consulting Psychologists Press.

Stein, M. B., Walker, J. R., Hazen, A. L., \& Forde, D. R. (1997). Full and partial posttraumatic stress disorder: Findings from a community survey. American Journal of Psychiatry, 154, 1114-1119.

Taft, C. T., Stern, A. S., King, L. A., \& King, D. W. (1999). Modeling physical health and functional status: The role of exposure, posttraumatic stress disorder, and personal resource attributes. Journal of Traumatic Stress, 12, 3-23.

Taft, C. T., Pless, A. P., Stalans, L. J., Koenen, K. C., King, L. A., \& King, D. W. (2005). Risk factors for partners violence among a national sample of combat veterans. Journal of Consulting and Clinical Psychology, 73, 151-159.

Verbosky, S. J., \& Ryan, D. A. (1988). Female partners of Vietnam veterans: Stress by proximity. Issues in Mental Health Nursing, 9, 95-104.

Waysman, M., Mikulincer, M., Solomon, Z., \& Weisenberg, M. (1993). Secondary traumatization among wives of posttraumatic combat veterans: A family typology. Journal of Family Psychology, 7(1), 104-118.

Westerink, J., \& Giarratano, L. (1999). The impact f PTSD on partners and children of Australian Vietnam veterans. Australian and New Zealand Journal of Psychiatry, 33, 841-847.

WHOQOL Group. (1998).World Health Organization Quality of Life Assessment (WHOQOL): Developmental and general psychometric properties. Social Science Medicine, 46, 1569-1585.

Wolfe, J., Schnurr, P. P., Brown, P. J., \& Furey, J. (1994). Posttraumatic stress disorder and war-zone exposure as correlates of perceived health in female Vietnam War veterans. Journal of Consulting Clinical Psychology, 62, 1235-1240.

Yehuda, R., \& Wong, C. M. (2002). Pathogenesis of posttraumatic stress disorder and acute stress disorder. In D. J. Stein \& E. Hollander (Eds.), Textbook of Anxiety Disorders (pp. 374-385). Washington, DC: American Psychiatric Publishing.

Zatzick, D. F., Marmar, C. R., Weiss, D. S., Browner, W. S., Metzler, T. J., Golding, J. M., . . Wells, K. B. (1997). Posttraumatic stress disorder and functioning and quality of life outcomes in a nationally representative sample of male Vietnam veterans. American Journal of Psychiatry, 154, 1690-1695. 